\title{
Perspectivas curriculares CTS para o ensino de engenharia: uma proposta de formação universitária
}

\author{
Irlan von Linsingen \\ Universidade Federal de Santa Catarina
}

\section{Resumo}

A formação em engenharia pautada apenas por competência técnica é problematizada, e possibilidades de transformação educacional propiciadas pelas dimensões sociocultural, sociotécnica e ambiental do conhecimento são tratadas a partir dos estudos CTS, dos estudos pós-coloniais e da educação crítica. É apresentada uma proposta de estrutura acadêmica para um novo câmpus da Universidade Federal de Santa Catarina, articulada em três eixos que favorecem interações entre os campos disciplinares técnicos e das ciências humanas ao longo da formação, em disciplinas específicas e demais atividades curriculares, buscando reduzir a separação abissal entre o técnico e o sociocultural na engenharia.

Palavras-chave: Formação tecnológica. Educação CTS. Currículo. Cidadania sociotécnica. Estudos CTS. 


\section{Engineering curricula in university education: an overview taking into account social studies of science and technology}

Engineering education guided only by technical competence is problematized and educational transformation opportunities afforded by the sociocultural, sociotechnical and environmental dimensions of knowledge are treated, based on STS studies, postcolonial studies and critical education. A proposed academic structure for a new campus of the Federal University of Santa Catarina is presented, joining three axes that favor interactions between technical disciplines and the humanities throughout the training in specific disciplines and other curricular activities, seeking to reduce the abyssal separation between the technical and the sociocultural in engineering.

Keywords: Technological education. STS education. Curriculum. Sociotechnical citizenship. STS studies.

\section{Perspectivas curriculares CTS para la educación en ingeniería: una propuesta para la educación universitaria}

La enseñanza de la ingeniería guiada solo por competencia técnica es puesta en cuestión y las oportunidades de transformación educativas que presentan las dimensiones sociocultural, sociotécnica y ambiental del conocimiento son tratadas desde los estudios CTS, los estudios poscoloniales y la educación crítica. Se presenta una estructura académica para un nuevo campus de la Universidad Federal de Santa Catarina, articulado en tres ejes que favorecen la interacción entre las asignaturas técnicas y de las ciencias humanas al largo de la formación en las asignaturas específicas y otras actividades curriculares, con el objetivo de reducir la separación abismal entre lo técnico y lo sociocultural en la ingeniería.

Palabras-clave: Formación tecnológica. Educación CTS. Currículum. Ciudadanía sociotécnica. Estudios CTS. 


\section{Introdução}

A formação de engenheiros e tecnólogos, mais do que buscar preparar agentes de inovação tecnológica eficientes, deve ser pensada sob a ótica da inovação sociotécnica, que visa preferencialmente à efetividade de processos, serviços e produtos relacionados aos interesses e necessidades dos mais diferentes grupos sociais. Nesse sentido, qualquer estratégia de capacitação para a inovação deve necessariamente considerar a natureza sociocultural do conhecimento científicotecnológico a ser construído/apropriado pelos atores de inovação sociotécnica.

Neste artigo discuto aspectos da qualificação profissional em engenharia pautada na exclusiva competência técnica. Abordo possibilidades de transformação propiciadas pela perspectiva de associar à formação tecnocientífica as dimensões sociocultural e ambiental. Considero que a educação tecnológica deve trabalhar com a perspectiva de inclusão sociotécnica, que trate simetricamente conhecimento tecnológico e contexto sociocultural em que aquele se desenvolve, transformando-os.

A formação no contexto da inovação sociotécnica é tratada a partir dos estudos sociais da ciência e da tecnologia, ou estudos CTS (ECTS) e o que eles apresentam para transformações significantes no ensino de engenharia, na perspectiva de atendimento do que é proposto nas diretrizes curriculares brasileiras (DCNs). Trata-se de tornar aparentes alguns obstáculos interpostos à educação em engenharia, decorrentes da assunção de uma concepção restrita ou equivocada das relações ciência-tecnologia-sociedade, que orienta implicitamente os processos de formação de engenheiros. Extraio dos ECTS contribuições para a incorporação de fatores explicativos das múltiplas imbricações da engenharia, numa dimensão até agora mantida apartada do seu ensino por supostamente não lhe dizer respeito, que é a dimensão sociotecnológica. Parto da problematização do processo de formação de engenheiros orientado para uma visão tecnocêntrica da tecnologia, que inibe a construção de capacidades de inovação sociotécnica, restringindo substancialmente o campo de atuação dos engenheiros.

Para a efetivação dessa perspectiva formativa, apresento uma proposta de estrutura acadêmica para um novo câmpus da Universidade Federal de Santa Catarina, em Blumenau, pensada desde uma perspectiva que contemple as interações sociotécnicas ao longo da formação, nas atividades curriculares e extracurriculares, tanto no contexto das inter-relações entre os campos disciplinares técnicos e das ciências humanas previstos em sua estrutura, quanto no âmbito de disciplinas específicas da área técnica, buscando reduzir e superar a histórica e ilusória separação abissal entre o técnico e o sociocultural existente nos cursos de engenharia. 
O objetivo é propiciar uma formação em engenharia com orientação sociotecnológica, com enfoques educacionais socioculturalmente referenciados e comprometidos da atividade científico-tecnológica, visando à superação dos silenciamentos decorrentes de uma visão restrita do campo de atuação profissional, e, também, contribuir para o debate atual em torno do desenvolvimento sustentável e da formação dos agentes de inovação social.

\section{Os estudos CTS como referenciais}

Crenças e pressupostos que sustentam atitudes hegemônicas no ensino de engenharia e dificultam o envolvimento dialógico de especialistas técnicos com diferentes atores sociais, seja no âmbito das políticas públicas, seja na atuação profissional privada, necessitam ser explicitados para compreender onde e como se originam e consolidam.

Para explorar as causas de obstáculos interpostos à educação em engenharia utilizo os referenciais dos estudos CTS (ECTS), como consequência da assunção de uma concepção restrita da natureza sociocultural do conhecimento tecnológico e das limitações formativas daí decorrentes.

De partida é assumido que tais crenças e pressupostos são tidos como autoevidentes na área técnica, a ponto de serem considerados "naturais" na atividade da engenharia, de modo que não chegam a constituir, em princípio, questões que poderiam ser formalmente consideradas como pontos de inflexão que justificassem a abertura de um campo de estudos próprio, destinado à compreensão da coisa técnica e das inter-relações que ela engendra. Os problemas técnicos, por essa ótica, requerem apenas soluções técnicas em sentido estrito, para as quais existem metodologias laboriosamente estruturadas. (Linsingen, 2007)

Trata-se, evidentemente, de uma posição que expressa uma visão internalista - e em muitos casos ingênua - da engenharia, a partir da qual problemas (sociotécnicos) percebidos/definidos por atores específicos lengenheiros, pesquisadores, empreendedores) são reduzidos a problemas técnicos frequentemente bastante complexos, com a eliminação de todos os aspectos ditos não técnicos, o que equivale dizer, nesse contexto, socioculturais.

A posição a esse respeito aqui defendida é que, ao contrário, a indissociável natureza social e cultural da tecnologia provoca a emergência de contradições naqueles pressupostos que afeta o que, o como e o para que fazer da engenharia, com evidente ressonância na sua estrutura pedagógica, requerendo uma nova forma de abordagem do processo de formação tecnológica. 
A identificação e problematização desses pressupostos, no campo disciplinar, pressupõe operar sobre uma base "externa" do conhecimento da engenharia. É aqui que os referenciais dos estudos CTS tornam-se valiosos para a explicitação de especificidades socioculturais e socioeconômicas regionais que permitem realizar abordagens educacionais contextualizadas, socialmente referenciadas e comprometidas em termos curriculares, e que possibilitam a ampliação da visão do campo de atuação das engenharias, principalmente no que se refere aos seus comprometimentos sociais e culturais mais amplos. Isto é cabível e teoricamente pertinente desde a perspectiva das propostas centrais dos ECTS. Assim, as contribuições dos ECTS latino-americanos (Linsingen, 2007) são muito importantes para as articulações significantes da pesquisa em educação de países da América Latina.

Somados a essas novas compreensões das relações CTS, também os estudos pós-coloniais possibilitam uma contextualização do ensino, estabelecendo uma conexão estreita com o pensamento CTS crítico e o que ele pode proporcionar em termos de alternativas para uma educação científica e tecnológica emancipatória e socialmente inclusiva.

Essa proposta educacional ocupa-se, desse modo, a trabalhar no âmbito das especificidades sociais-culturais e políticas de países com características que se aproximam em termos de relações de colonialidade de saber/poder. (Mignolo, 2003; Castro-Gómez; Grosfogel, 2007; Santos; Meneses, 2010)

Isso quer significar que, ao nos referimos à educação CTS, apontamos para questões que envolvem os variados aspectos das relações sociais, culturais e econômicas globais e regionais que abarcam o campo das políticas públicas de C\&T com suas percepções de relevância e também estamos a considerar as questões de natureza étnica e de gênero na configuração das relações de saber/ poder favorecidas pela ciência-tecnologia.

$\mathrm{Na}$ educação em geral, e ainda que timidamente na educação em engenharia, é perceptível a intensificação de abordagens alternativas no ensino de ciências e tecnologia e também da discussão de necessidades nos diferentes níveis de formação, considerando suas especificidades e finalidades, sob influência dos ECTS. A práxis educacional constitui-se de uma mescla de concepções CTS, composta tanto pela concepção tradicional das relações entre ciência-tecnologiasociedade quanto por concepções mais progressistas e críticas, sem uniformidade entre os diversos níveis e modalidades de ensino. Contudo, é notável a prevalência da concepção tradicional na conformação dessa práxis, o que fortalece resistências ao processo de construção de alternativas educativas ao modelo sociotécnico dominante. A proposta apresentada aqui visa superar tais resistências.

Para ajudar a problematizar essas questões relacionadas à formação 
tecnológica, recorro a Pimenta e Anastasiou (2005) que, ao se referirem à formação de professores brasileiros, afirmam que, no modelo em que se pauta o ensino superior, sempre ficou reforçada a visão de que o senso comum (que entendo como saberes locais, consuetudinários, ancestrais, tácitos...) era algo sem valor e que deveria ser combatido mediante um conhecimento científico neutro e verdadeiro; cabia ao sujeito aprendê-lo com a maior objetividade possível. Nesse sentido, as práticas destinadas à formação profissional, particularmente a tecnológica, costumam se restringir à apresentação de conteúdos das ciências ditas básicas numa fase de formação e mais adiante os conteúdos técnicos nas disciplinas aplicadas, sem levar em conta as culturas e os saberes locais, a simetria que deveria haver, o diálogo de saberes.

Nesse sentido, além de reconhecer os aspectos problemáticos que circundam a educação em geral, especialmente em termos dos processos de elaboração e de inserção de currículos e das limitações do processo de formação profissional, incluídas as de professores das áreas técnicas e a formação para a cidadania, problematizo o cenário posto para apontar novas possibilidades.

Essas questões podem ser tratadas como reflexos de um processo mais amplo, que parte do que alguns autores tratam como globalização (e seus efeitos), tais como a transnacionalização, a educação assistencialista e o neocolonialismo, por meio da colonialidade do poder, de modo que é importante aprofundar os sentidos relacionados a cada uma destas expressões/noções, a partir do enfoque de autores que se debruçam a estudá-las.

Este movimento unilateral e verticalizado da abordagem do conhecimento científico e tecnológico, com imposição de ideias na formação de professores de ciências (e de engenheiros-professores), também pode ser considerado a partir da ótica de uma transnacionalização da educação, que, ao desconsiderar a voz dos grupos sociais e culturais a que se destina, pode vir a se constituir neocolonial ou subalterna. Alguns autores (Ortiz, 1994; Dale, 2004) situam a transnacionalização como a transferência de saberes e ideias pensadas/planejadas em outras situações e nações, para uma nação em desenvolvimento ou ainda em fase de estruturação. Em Ortiz (1994) esta noção teve início a partir do processo por ele denominado de transculturação, com efeitos de sentido naturalizados nos modos de pensar e agir na área tecnológica e, por isso, pouco evidentes.

Tais referências são pertinentes porque neste âmbito se efetiva a formação pedagógica daqueles que também serão professores das áreas técnicas, além de outras ações como a produção de materiais didáticos, e, principalmente, porque aqui é abordada uma concepção de ciência e tecnologia menos estática e mais problematizadora, que dialogue com as realidades locais, considerando que as pressões das políticas científicas e tecnológicas são, em muitos aspectos, não 
compatíveis com as condições culturais e econômicas do país a que se destinam.

Numa perspectiva mais focada nos ECTS latino-americanos, trata-se também de pensar numa endogenização da tecnologia, vista como assimilação crítica e criativa, como processo mediante o qual seriam ressignificadas características da tecnologia nos países periféricos, o que não exclui a sua importação, mas que esta seja adequada às demandas definidas por uma política de C\&T com compromissos sociais amplos (Vessuri, 2001). Nesse sentido, a transferência de tecnologia transforma-se em parte do processo de assimilação/geração de tecnologia (Herrera, citado por Dagnino, 2000). Não há nesse processo a intenção de um encapsulamento da sociedade que opta por um desenvolvimento científico e tecnológico desse tipo, mas implica conquistar autonomia para definir de que maneira essa sociedade particular deseja funcionar, em que base tecnológica deseja construir-se.

Em nível ideológico trata-se, entre outras coisas, de um processo de ruptura com a visão tradicional de ciência e de tecnologia coloniais, com vistas a uma ressignificação radical, "o assumir a ciência como cultura, o passar do predomínio de atores sociais que são 'porteiros' que abrem as portas para as tecnologias forâneas do mundo desenvolvido ao apogeu de vetores tecnológicos endógenos, o reestruturar disciplinas científicas que constituem reservatórios de conhecimentos elaborados por outras culturas, a reavaliação do sentido comum local e a reconstrução de tradições, assim como a participação social na criação de tecnologia". (Vessuri, 2001, p. 242)

Contudo, para poder mudar é preciso reconhecer onde se escondem as resistências, torná-las visíveis, debatê-las e, a partir daí, buscar formas mais adequadas a critérios democraticamente escolhidos.

\section{A concepção clássica de C\&T e a perspectiva da engenharia}

A forma tradicional de entendimento conceitual da ciência e da tecnologia como atividades autônomas, neutras e benfeitoras, aliadas à herança colonial, continua a ser utilizada na academia para legitimar suas atividades. Para González García, Cerezo e Luján, "é esta concepção tradicional, assumida e promovida pelos próprios cientistas e tecnólogos, a que em nossos dias continua sendo usada para legitimar formas tecnocráticas de governo e continua orientando o projeto curricular em todos os níveis de ensino". (González García; Cerezo; Luján,1996, p. 26)

A engenharia, em termos gerais, desenvolve-se nos mais diversos contextos e nas mais diferentes condições e, nesse sentido, é pertinente pensar a engenharia como atividade diretamente relacionada a processos de transformação, ligada ao 
que fazer da sociedade - e, portanto, relacionada à cultura -, o que lhe confere um estatuto próprio de atividade de inúmeras faces e finalidades e, por isso, com um vasto campo de ação, aberto e em construção.

Nesse sentido, apesar de fortes ligações, a engenharia não possui compromisso exclusivo com a empresa e a indústria, como se esforça por fazêlo o poder hegemônico - já de dentro das instituições de ensino -, caso em que emerge sutil, mas firme, a defesa do supostamente intrínseco caráter neutro e benfeitor da atividade. Com isso reduzem-se as chances de reconhecimento do necessário desenvolvimento de capacidade crítica do engenheiro ou, o que se tornou frequente, atribuir-se a este apenas o caráter de crítica do produto técnico, ou seja, restrita a uma percepção específica de desenvolvimento tecnológico, característico do feitio internalista que se atribui à atividade. Essa defesa se dá normalmente pela via cruel da indiferença, do não debate, da não problematização que oculta as interações substantivas lou os envolvimentos mais amplos) da engenharia.

Nos sentidos aqui expostos, o currículo de engenharia possui um compromisso com a generalidade, além daquele que já possui com a especificidade. Mas, mais do que generalidade, esse mesmo currículo deve se ocupar com a natureza sociocultural do conhecimento da engenharia, complexidade que emerge das imbricações da engenharia com aqueles atores sociais que estão silenciados, ou invisibilizados.

As diretrizes curriculares para as engenharias no Brasil sugerem a abordagem dessa perspectiva lartigo $\left.3 .{ }^{0}\right)^{1}$. Entretanto, a implementação dessas transformações, a maioria delas fruto de pressões externas (de outros atores sociais), exige uma ressignificação das práticas seculares da engenharia. 0 fato é que não há correspondência entre a prática pedagógica e as concepções de mudança expressas nas diretrizes. Há certamente razões bastante fortes para que isso aconteça desse modo, e provavelmente as mais importantes estariam relacionadas às assunções que se manifestam na defesa de pressupostos históricos associados com essa prática. Por essa razão, a abordagem temática e os estudos de caso que tratam das controvérsias sociotécnicas e sociocientíficas, oriundos dos ECTS, podem ser muito significativos para a desnaturalização e explicitação daquelas tendências, já que a sua aceitação e o contexto das intervenções que se manifestam a partir deles são mais próximos e por isso mais aceitáveis pelos atores da área técnica. 


\section{Os estudos CTS e o espaço de relações da engenharia}

Os estudos CTS constituem um campo de trabalho de caráter crítico com relação à tradicional imagem essencialista da ciência e da tecnologia, e de caráter interdisciplinar para o qual concorrem disciplinas como a filosofia da ciência e da tecnologia, a sociologia da ciência e da tecnologia, a teoria da educação e a economia da mudança tecnológica. Os ECTS buscam compreender a dimensão social da ciência e da tecnologia, tanto do ponto de vista de seus antecedentes sociais como de suas consequências sociais e ambientais, quer dizer, tanto no que toca aos fatores de natureza social, política ou econômica que modulam a mudança científico-tecnológica, como no que concerne às repercussões éticas, ambientais ou culturais dessa mudança.

Como a caracterização desse enfoque das relações ciência-tecnologia-sociedade é fundamentalmente contrária à imagem tradicional da C\&T - assumida como atividade autônoma que se orienta exclusivamente por uma lógica interna e livre de valorações externas -, na medida em que transfere o centro de responsabilidade da mudança científico-tecnológica para os fatores sociais, o fenômeno científico-tecnológico passa a ser entendido como processo ou produto inerentemente social em que os elementos não epistêmicos ou técnicos (como valores morais, convicções religiosas, interesses profissionais, pressões econômicas etc.) desempenham um papel decisivo na gênese e consolidação das ideias científicas e dos artefatos tecnológicos.

Em termos de ensino de engenharia, essa mudança de eixo pode significar uma transformação radical nos processos cognitivos, na medida que a atividade engenheiril, pensada como atividade meio, passaria a ser orientada por uma lógica distinta da que hoje a estrutura, orientada para a técnica como meio e não um fim em si mesma. $E$, se acrescentarmos a essa percepção o reconhecimento da natureza cultural dos conhecimentos, a tecnologia se configura nas socioculturas, não podendo mesmo ser entendida como universal.

Por seu turno, a relação entre tecnologia e sociedade, para os engenheiros, apresenta-se tão profundamente enraizada que parece não haver qualquer razão para debates. Identificada com artefatos, e portanto com um dos produtos da atividade da engenharia, de uma suposta evidente imbricação, acabou por tornar-se oculta e, de modo mais contundente, não pertencente ao espaço da atividade técnica como tal, mas apenas ao espaço da ética da engenharia.

Nessa acepção, a imbricação entre tecnologia e sociedade esteve sempre presente por meio da própria definição de engenharia, como normalizadora da atividade, pelo menos até meados da década de 1990: a atividade da engenharia deve estar voltada para o bem-estar da sociedade. Mas já não se apresenta dessa maneira, tendo sofrido modificações para uma relação "mais flexível”, contexto-dependente (Mitcham, 
2001): em atendimento às "demandas da sociedade". Quem define as demandas e o que são essas demandas? Rapidamente essa conexão tende a transformar-se em mera retórica ética, ou em transferência de responsabilidade para outras áreas do conhecimento, justamente em razão de conflitos e contradições que a postura moral provoca com as novas relações de mercado e com os efeitos negativos ou duvidosos atribuídos à tecnologia. Em qualquer caso, na relação tecnologia-sociedade mantevese sempre uma rigidez dos limites de interação, ou seja, uma separação estratégica, já que valores e interesses mais implícitos, imagina-se, não pertencem ao campo da técnica, abrindo espaço para as atitudes tecnocráticas, o que teria sido plenamente absorvido pelo ideário da engenharia.

A pressão para a busca do status de excelência acadêmica na área de engenharia, indicativo do alinhamento da atividade acadêmica com as políticas de ciência e tecnologia nacionais e interesses parcelares, precipitou a emergência de tensões internas no que diz respeito à natureza da atividade acadêmica e ao caráter da formação profissional - com disputas curriculares -, como reflexos das disputas de poder. Essas tensões acabaram por fazer emergir contradições discursivas e comportamentais centradas precisamente em pressupostos de origem positivista e também em concepções alternativas sobre a natureza do conhecimento técnico e de sua finalidade e, em tal contexto, criaram-se condições propícias para a construção de uma estrutura curricular que praticamente elimina do processo de formação técnica as referencias sociais e os contextos em que a tecnologia se desenvolve.

A orientação CTS adotada neste artigo confere poder explicativo para muitas das indagações e inquietações relativas às imbricações da engenharia com a ciência, a tecnologia, a sociedade e a natureza, por um viés novo e quiçá mais sincrônico com o pensamento e as ações da área técnica, abordando temas que, embora façam parte da atividade da engenharia, normalmente não são considerados na formação tecnológica. É esse viés que permite identificar lacunas e obstáculos sócio-epistêmicos na formação técnica, como os decorrentes do não reconhecimento formal das imbricações sociais da técnica na formação de engenheiros, ou o da formação sociotécnica de caráter unilateralmente tecnocientífica, ou ainda o da não percepção de tecnologia como processo social e dos artefatos tecnológicos como construto sociocultural.

\section{CTS em nível universitário}

Em linhas gerais, no âmbito do ensino superior, os programas CTS têm sido oferecidos como especialização de pós-graduação (especialização, mestrado) ou como complemento curricular para estudantes de diversas procedências, e visam proporcionar uma formação humanística básica a estudantes de 
engenharia e ciências naturais. 0 objetivo é desenvolver nos estudantes uma sensibilidade crítica acerca dos impactos sociais e ambientais derivados das novas tecnologias ou a implantação das já conhecidas, formando por sua vez uma imagem mais realista da natureza social da ciência e da tecnologia, assim como do papel político dos especialistas na sociedade contemporânea.

Por outro lado, trata-se de oferecer conhecimentos contextualizados sobre ciência e tecnologia aos estudantes dos bacharelados e licenciaturas (Cassiani; Linsingen, 2009), com o objetivo de proporcionar a estes estudantes a construção de uma percepção crítica sobre ciência e tecnologia, de modo a participarem ativa e criticamente dos processos de decisão em política científica e tecnológica que os implicarão como profissionais e como cidadãos. Assim, essa educação deve capacitá-los a participar de forma frutífera em qualquer controvérsia pública ou em qualquer discussão institucional sobre tais políticas.

Uma ação disciplinar, com tratamento transversal, destinada a suprir parte dessa carência formativa para os alunos de todas as modalidades de engenharia constitui, e assim é aqui entendida, uma importante contribuição para uma formação voltada para a ampliação do comprometimento social da ciência e da tecnologia e, consequentemente, da engenharia. Ações que são consideradas importantes, nesse momento, passam pela estruturação de programas de formação de professores de engenharia e de políticas institucionais de fomento à formação CTS para professores de engenharia de todo o país, entre outras. A orientação, no entendimento aqui defendido, é que aspectos da história, da sociologia, da antropologia e da filosofia da ciência e da tecnologia deveriam consubstanciar os programas de formação de professores, além dos aspectos didático-pedagógicos (praticamente inexistentes ou desvirtuados nos atuais modelos de estágio-docência dos programas de pós-graduação).

Para o ensino de engenharia esta é uma condição necessária, mas não suficiente. Entendo ser necessário que, além de proporcionar formação humanística básica, conforme expresso anteriormente, o próprio conhecimento tecnocientífico deva ser conceitualmente transformado e que a sua preparação didática incorpore essas concepções da natureza social e cultural da ciência e da tecnologia, além dos tradicionais critérios econômicos e de eficiência já incorporados e dados como "naturais" e imanentes na técnica.

Nesse sentido, para consolidar uma formação em engenharia com comprometimentos sociais mais amplos, a dialogicidade na identificação/ definição de problemas e busca de soluções com os atores sociais historicamente excluídos dos processos de construção tecnológica, aqui pensado como processo de coconstrução de tecnologias, apresenta-se como potencialmente 
transformadora. Tal potencialidade, enfatizada em artigos que tratam da articulação dos ECTS com propostas educacionais críticas, como a de Paulo Freire (Nascimento; Linsingen, 2006), constitui uma ferramenta pedagógica relevante para a formação de engenheiros. As possibilidades da investigação temática freireana, pensadas desde os ECTS para estruturar os processos de coconstrução sociotécnica, podem ser muito úteis para a superação daqueles silenciamentos já citados, favorecendo a ressignificação dos sentidos de inclusão social no nível da formação universitária, no sentido de dar voz aos diferentes atores sociais com vistas à emancipação para consolidação de uma cidadania sociotécnica².

\section{Proposta de estrutura acadêmica para um novo centro de ensino da Universidade Federal de Santa Catarina}

Esta proposta de estrutura acadêmica para um novo câmpus da UFSC fundamenta-se em estudos e levantamentos sobre o contexto social e econômico da mesorregião do Vale do Itajaí (Secretaria de Estado da Assistência Social, Trabalho e Habitação: Diretoria de Trabalho, Emprego e Rendal e nos referencias dos estudos sociais da ciência e da tecnologia. (Linsingen, 2013)

0 objetivo geral é criar um centro de ensino universitário com abrangência para a mesorregião do Vale do Itajaí, considerando:

a) a função social da Universidade, no que concerne à produção de conhecimento e de inovações sociotécnicas, bem como sua responsabilidade no que concerne ao desenvolvimento de políticas voltadas para a inclusão social, em especial da juventude;

b) a adequação de seus objetivos àqueles que orientam o processo de expansão e de interiorização da Universidade;

c) a necessidade de democratização da universidade pública, o que implica a ampliação do ingresso e, também, o incentivo à permanência, com qualidade social referenciada, em cursos de graduação e de pós-graduação, que visem à formação para o mundo do trabalho com desenvolvimento do pensamento crítico, da cidadania, da ética, da cultura e da democracia.

2. Para uma abordagem mais detalhada sobre cidadania sociotécnica, ver Thomas (2001). 


\section{Relevância da proposta}

Estudos preliminares ${ }^{3}$ indicaram que uma das importantes demandas da mesorregião do Vale do Itajaí está historicamente relacionada à área têxtil. Por essa razão e também pelas potencialidades e reconhecimento dos cursos de engenharia da Universidade Federal de Santa Catarina, o oferecimento de um curso de engenharia têxtil é plenamente justificado.

Por determinação do MEC, o novo câmpus da UFSC deveria oferecer de início três bacharelados e duas licenciaturas, o que levou a buscar correspondências e interrelações entre os cursos e as demandas regionais, pensadas desde os objetivos apresentados anteriormente.

As discussões realizadas por professores convidados a participar do processo de estruturação do novo câmpus indicaram que a engenharia de materiais e a engenharia de controle e automação comporiam um elenco de cursos que favoreceriam a articulação entre esses e o de engenharia têxtil e atenderiam adequadamente as demandas regionais. Articuladas com essas três engenharias estão as licenciaturas em matemática e química. Entretanto, fica evidenciada a importância de se implementar, no médio prazo, uma licenciatura em física e, também, em biologia.

Para dar conta das demandas pelo desenvolvimento de políticas voltadas para a inclusão social, os currículos dos cinco cursos foram pensados desde uma perspectiva que formalmente incluísse temas das ciências humanas e sociais previstos nas DCNs. Dessa forma, o sentido de inclusão social, apresentado nos objetivos, remete à inclusão do campo dos estudos sociais da ciência e da tecnologia na formação dos engenheiros e dos licenciados. A concretização dessa articulação foi favorecida pela introdução de um eixo que trabalhasse as questões relativas ao desenvolvimento regional e interação social como componentes fundamentais para esses cursos.

\section{Estrutura do câmpus}

Dos elementos anteriormente apresentados emergiu a concepção de estrutura para o novo câmpus UFSC.

Em essência, o câmpus se estrutura em três eixos principais, que deverão trabalhar de forma articulada, objetivando formar profissionais com perfil adequado para o atendimento das demandas sociotécnicas da mesorregião do Vale do Itajaí, como apresentado anteriormente. Graduação e pós-graduação são, nessa estrutura,

3. Apresentados por Leandro Santos e Pietro Caldeirini Aruto no Boletim Regional do Mercado de Trabalho Mesorregião Vale do Itajaí, Série 2013, n. ${ }^{0} 1$. 
elementos indissociáveis. A pós-graduação é, ademais, um elemento de fixação dos professores e de ampliação e aprimoramento contínuo do câmpus. A figura 1 a seguir apresenta a proposta de estrutura.

Figura 1: Estrutura proposta para o câmpus UFSC-Blumenau

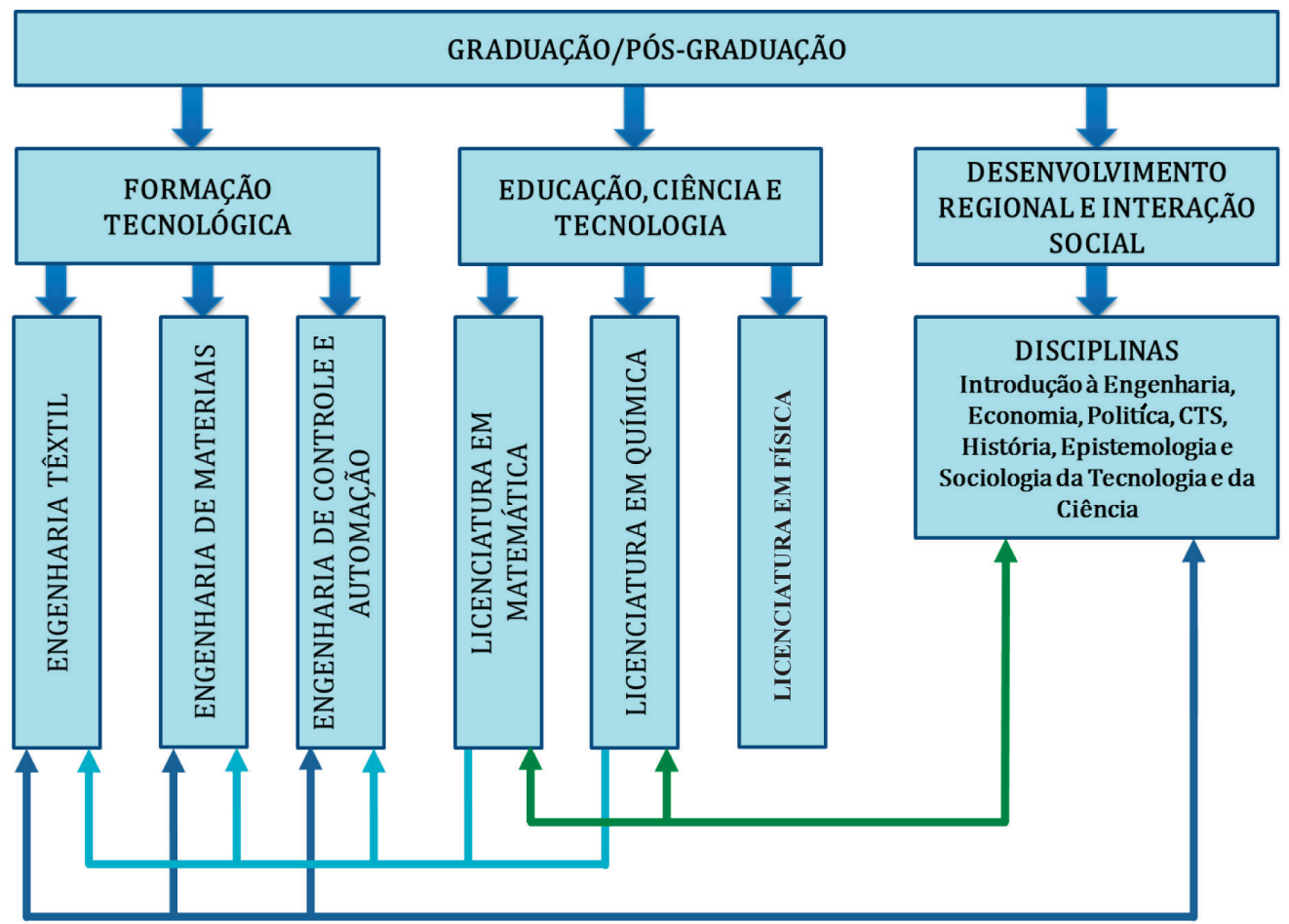

Fonte: Linsingen, 2013

\section{EIXO 1: FORMAC̣ÃO TECNOLÓGICA:}

BACHARELADOS: engenharia têxtil - engenharia de materiais - engenharia de controle e automação.

\section{EIXO 2: EDUCAC̣ÃO, CIÊNCIA E TECNOLOGIA:}

LICENCIATURAS: matemática e química, com perspectiva futura de licenciatura em física e em biologia. 


\section{EIXO 3: DESENVOLVIMENTO REGIONAL E INTERAÇÃO SOCIAL:}

Embora sem cursos definidos para a fase inicial, este eixo deve resolver em parte a questão das interfaces entre os 5 cursos, propor e organizar as atividades de interação social, incentivar as relações de cooperação entre os grupos sociais, setores econômicos/produtivos e a comunidade em geral e planejar estratégias de interação a partir de ideias de ação colaborativa e dialogo de saberes. Para atendimento das demandas dos cursos, é prevista a contratação de professores das ciências humanas e sociais aplicadas (filosofia e sociologia da ciência e da tecnologia, estudos sociais sobre a ciência e a tecnologia (CTS), política, antropologia e história das tecnologias e das ciências). Desempenharão papéis dentro e fora dos cursos para pensar essas relações com diferentes grupos sociais relevantes e pensar programas de pós-graduação voltados aos 3 eixos. Deverão atuar também com disciplinas de introdução à engenharia, CTS, economia, política, história, epistemologia e sociologia das tecnologias e das ciências.

\section{Aspectos fundamentais da estrutura do câmpus: conclusões}

A formação de engenheiros vem sendo bastante incentivada nas políticas públicas de educação. 0 aumento de vagas em cursos de engenharia bem como o aumento no número de engenheiros formados tem sido entendido como condição necessária para o crescimento econômico brasileiro. De acordo com levantamentos da Confederação Nacional da Indústria, CNI, para dar conta da demanda por esses profissionais, seria necessário formar 60 mil engenheiros por ano no Brasil. Entretanto, apenas 32 mil obtêm este diploma a cada ano. Esta crescente demanda por engenheiros é atribuída à retomada do crescimento econômico, à necessidade brasileira de ampliação da infraestrutura e às novas perspectivas econômicas, como por exemplo os novos desenvolvimentos na exploração de petróleo.

Porém, levando-se em conta as transformações sociais e políticas que têm provocado na sociedade brasileira o interesse expresso de reduzir injustiças sociais e orientar ações no sentido de ampliar a inclusão social 4 , a formação de engenheiros deverá incluir, necessariamente, aspectos até agora pouco explorados nessa formação. Pouco se discute, nesse contexto, que engenheiro

4. Como o termo "inclusão social” é polissêmico, refiro-me aqui à inclusão nos termos que são adotados pela tecnologia social (Dagnino, 2010) e em conformidade com as perspectivas dos estudos pós-coloniais.

(Santos;Meneses, 2010) 
é preciso formar, para quê e para quem. Admitindo que esse direcionamento provoca uma ampliação na demanda por engenheiros, essa necessidade numérica apresentada pela CNI estaria subdimensionada.

Para esse mesmo contexto de necessidades sociais e políticas, a formação de professores de ciências e matemáticas, que é também foco desse novo câmpus, deverá se pautar pelos mesmos princípios orientadores.

A formação de engenheiros está historicamente vinculada ao modelo linear de desenvolvimento, para o qual mais investimento em ciência produziria mais desenvolvimento tecnológico, que alavancaria o crescimento econômico e, por consequência, produziria mais desenvolvimento social. Nesse sentido, a formação de engenheiros deveria ser orientada ao atendimento daquelas demandas técnico-econômicas e, para tal, essa formação deveria atentar prioritariamente, senão exclusivamente, para a máxima eficiência técnicocientífica, pois esta seria suficiente para o melhor atendimento daquelas demandas e, imagina-se, por consequência estratégico para a redução das desigualdades sociais.

Entretanto, faz mais de vinte anos que os estudos sociais e políticos da ciência e da tecnologia têm mostrado enfaticamente a ineficácia explicativa e operacional do modelo linear de desenvolvimento para o desenvolvimento das sociedades, indicando por consequência as deficiências da formação de engenheiros para o atendimento das demandas sociotécnicas e, também, da formação de professores de ciências.

Nesse sentido, tão importante quanto o atendimento daquelas demandas técnico-econômicas, está a atuação de engenheiros para o atendimento das demandas sócio-tecnológicas, considerando que a tecnologia é uma dimensão fundamental para a compreensão das dinâmicas de inclusão e exclusão social. (Thomas, 2011)

Considerando que as sociedades são tecnologicamente construídas, ao mesmo tempo que as tecnologias são socialmente configuradas, a relação problema/solução passa necessariamente por compreender que os problemas, assim como as soluções, são construídos socialmente a partir da interação com os diferentes grupos sociais. É da compreensão de que todos os indivíduos possuem conhecimentos que emerge a necessidade de formar engenheiros com a capacidade de trabalhar com os sentidos da alteridade na identificação e solução de problemas sociotécnicos. Nesse sentido, diálogo de saberes e cooperatividade são elementos-chave na formação de engenheiros. Também o são as concepções de adequação sociotécnica e arranjo sociotécnico. (Dagnino, 2010; Thomas, 2011)

0 mesmo serve à formação de professores, que convém ser estruturada 
nesse contexto de relações ciência-tecnologia-sociedade em articulação com os estudos CTS (ECTS). Desse modo, os distintos aspectos dessas construções históricas podem ser desnaturalizados e problematizados, para construir novos sentidos sobre essas relações e suas repercussões na educação, em geral, e na educação científica e tecnológica, em particular.

Existem múltiplas estratégias possíveis que vinculam produção de conhecimento, inovação e desenvolvimento social. Enquanto algumas passam pelas relações universidade-empresa, outras passam pela relação problema-solução de necessidades sociais, questões ambientais, acesso aberto ao conhecimento. Os estudos sobre sistemas de inovação mostram, sem exceções, que as empresas capitalistas "flutuam" em oceanos amigáveis de processos sociais de aprendizagem, relações usuário/produtor, dinâmicas locais de inovação e produção, sistemas educativos e satisfação e criação de necessidades locais. Sem sociedades locais não há inovação. Sem processos sociais de aprendizagem não há empresas inovadoras. Por outro lado, empresas "flutuam" em oceanos de espaço público. Se esse espaço público não se coconstrói com a evolução dessas firmas, a inovação empresarial resulta, mais uma vez, inviável.

Grande parte do que ocorre em uma empresa capitalista guarda relação direta com o seu entorno. Porém, grande parte do que ocorre nesse entorno é muito mais que microeconomia de mercado. Basta pensar na estrutura de serviços públicos leletricidade, água, combustível, comunicações, transportes, saúde, segurança, administração públical para ter realçada a importância do espaço público para a compreensão das dinâmicas de desenvolvimento. Claro que para isso é necessário revisar as próprias noções de "desenvolvimento", observando que, no melhor dos casos, as relações tecnoprodutivas empresariais são apenas um aspecto da construção de uma dinâmica social. E parte do problema é que a "miopia neoclássica", que prioriza as relações empresariais sobre o resto das relações econômicas e sociais, tende a desatender os processos de constituição e evolução desse espaço público, e das relações sociotécnicas que esta implica. Neste plano, a geração de tecnologias sociais constitui uma questão-chave a explorar e aprofundar, como tratado por Thomas. $(2011)^{5}$

Em suma, não se trata de fazer mais do mesmo, mas de ampliar as possibilidades tecnológicas num universo de diversidade sociotécnica.

Em consonância com a orientação teórica apresentada anteriormente, é

5. Faço um agradecimento ao colega e amigo Hernán Thomas, professor da Universidade Nacional de Quilmes, que, com suas agudas percepções e críticas, tornou possível a construção dessa proposta. 
importante considerar que não se trata apenas de incluir disciplinas de CTS e das humanidades na matriz disciplinar das engenharias.

A proposta, ao estabelecer uma articulação formal e efetiva entre os eixos de formação tecnológica e de desenvolvimento regional e interação social, promove alterações substantivas no modo de estruturar as disciplinas técnicas, notadamente as de introdução à engenharia, que entendo serem de fundamental importância para os objetivos de formação aqui propostos, do mesmo modo que criam as condições para uma definição colegiada interdisciplinar dos estágios curriculares, trabalhos de conclusão de curso e demais atividades extracurriculares, que repercutirão na formação mais ampla do engenheiro e na percepção ampliada de seu campo de atuação. Nesse sentido, a definição das atividades, assim como dos locais onde serão desenvolvidas, passa a ser tarefa do coletivo de atores do centro de ensino, nesse caso, de comissão interdisciplinar composta por professores dos três eixos estruturantes.

Essas possibilidades de interação interdisciplinar estão incluídas nos projetos pedagógicos dos cursos (PPCs). Para citar um exemplo6, para o curso de engenharia têxtil, são obrigatórias as disciplinas de ciência-tecnologia-sociedade; tecnologia, inovação, desenvolvimento e sociedade; e as optativas propostas são: teoria do conhecimento para engenharia; tecnologias para o desenvolvimento inclusivo - desenvolvimento de tecnologias para a resolução de problemas sociais e ambientais -; políticas públicas, estratégias institucionais, desenho de artefatos e sistemas; sociedade, tecnologia e história, num total de 252 horas/aula distribuídas ao longo do curso.

Ainda como exemplo dessa interação, no projeto pedagógico deste curso estão previstas as práticas curriculares de inovação e desenvolvimento regional e interação social (PIDRIS), que visam promover uma maior aproximação dos alunos com os interesses de amplos segmentos sociais (ONGs, cooperativas, nichos familiares, prefeituras, microempresas, médias e grandes empresas). A carga horária destinada a essas atividades é de 90 horas-aula ao longo do curso, que são realizadas no âmbito de disciplinas obrigatórias tais como: ciência dos materiais têxteis, engenharia dos polímeros e das fibras II, gestão ambiental em organizações, engenharia do vestuário I e laboratório de criação de coleções I.

Para efetivar essa concepção em uma proposta pedagógica de práticas e currículo definem-se, em torno do eixo de desenvolvimento regional e interação social, as linhas de formação para a inovação e interação sociotécnica. Para

6. Extratos do projeto pedagógico oficial do curso de engenharia têxtil do câmpus UFSC-Blumenau ljulho de 2013). 
essas duas linhas, admite-se grande interconexão entre conteúdos ditos técnicos e a capacidade de propor "soluções que impactem na cadeia produtiva ou na rede social", de modo que as disciplinas com horas destinadas às PIDRIS são essenciais para desenvolver no futuro engenheiro a capacidade de "traduzir as demandas sociais, ambientais e econômicas em critérios técnicos" e "propor soluções inovadoras e sustentáveis", planejando ações e métodos para sua execução ${ }^{7}$. Na perspectiva da interação sociotécnica, busca-se “desenvolver um olhar voltado para todas as realidades sociais, econômicas e culturais da região. Nesta linha, as disciplinas com PIDRIS podem ser desenvolvidas em conjunto com os demais cursos de engenharia e de licenciatura, de modo a estimular uma visão plural. Além das disciplinas especificas desta linha, devem ser trabalhadas atividades acadêmico-científico-culturais de imersão social. Nestas atividades, os alunos poderão, sob supervisão de professores do curso, realizar, em grupo, uma imersão em uma comunidade ou região, seja como observador, seja como participante de pesquisa-ação, pesquisando temas geradores que servirão" para a construção coletiva de problemas e busca de soluções, "visando promover a maior participação social nas tomadas de decisão e na solução de problemas locais".

Para o trabalho de conclusão de curso, que possui carga horária de 60 horas (72 horas-aula), considerando o seu caráter formativo amplo, os “temas deverão ser definidos em articulação com o eixo de desenvolvimento regional e interação social", em conformidade com a estrutura proposta para o câmpus, apresentada anteriormente. Para tal, “as atividades serão reguladas por documento específico produzido por comissão interdisciplinar designada para este fim, composta por professores dos três eixos estruturantes do câmpus UFSC-Blumenau e pelo diretor acadêmico do câmpus".

0 estágio curricular obrigatório, com 600 horas (720 horas-aula), indispensável para a integralização curricular, e o estágio curricular não obrigatório são atividades acadêmicas entendidas como ato educativo escolar supervisionado, sendo desenvolvidas em ambiente de trabalho, e visam à preparação do educando para o trabalho produtivo, sob “orientação de um professor do curso e acompanhamento, quando couber, de um representante da comunidade lorganização/empresa/ instituição) à qual a atividade estará vinculada. As atividades são reguladas por documento específico produzido por comissão interdisciplinar designada para este fim, composta por professores dos três eixos propostos para a estrutura do câmpus UFSC-Blumenau e pelo diretor acadêmico do câmpus".

As atividades acadêmico-científico-culturais, com carga horária mínima de 
180 horas-aula, são componentes obrigatórios constantes da estrutura curricular dos cursos, tendo por finalidade proporcionar uma “complementação de conteúdos ministrados e/ou atualização permanente dos alunos acerca de temas emergentes relacionados à sua formação". Tais atividades visam "estimular o acadêmico a participar de atividades independentes, transversais, opcionais, de interdisciplinaridade, realizadas tanto no âmbito educacional quanto fora dele, de forma que possam contribuir para o aprimoramento pessoal e profissional dele. Constituem-se, portanto, em componentes curriculares enriquecedores e implementadores do próprio perfil do formando".

Para finalizar, articulada com essas ações e para que elas possam ser potencialmente transformadoras, é proposta paralelamente uma adequada formação em serviço de professores, que começa por um programa de formação institucional para o período do estágio probatório de três anos (PROFOR) e que, coerente com a natureza das transformações contínuas dos conhecimentos e da sociedade, deve seguir ao longo da vida acadêmica, envolvendo, entre outros, os vários aspectos da natureza sociocultural do conhecimento científico e tecnológico, da atividade didático-pedagógica, da natureza, estrutura e finalidades da universidade num país com especificidades socioculturais e socioeconômicas, como o Brasil.

\section{Referências}

CASSIANI, Suzani, LINSINGEN, Irlan von. Formação inicial de professores de Ciências: perspectiva discursiva na educação CTS. Educar em Revista, Editora da UFPR, Curitiba, Paraná, 2009.

CASTRO-GÓMEZ, Santiago; GROSFOGUEL, Ramón. (Editores). El giro decolonial. Reflexiones para uma diversidade epistémica más allá del capitalismo global. Bogotá: Siglo del Hombre Editores; Universidad Central; Instituto de Estudios Sociales Contemporáneos y Pontifícia Universidad Javeriana, Instituto Pensar, 2007.

DAGNINO, Renato Peixoto. (Org.). Tecnologia Social: ferramenta para construir outra sociedade. 2. ed. rev. e ampl., Campinas, SP: Komedi, 2010.

(Org.). Amilcar Herrera: um intelectual latino-americano. Campinas: Unicamp/IG/DDCT, 2000.

DALE, R. Globalização e Educação: Demonstrado a Existência de uma “Cultura Educacional Mundial Comum" ou Localizando uma "Agenda Globalmente Estruturada para a Educação?" Educação e Sociedade. Campinas, SP, v.25, n.87, pp.423-460, maio/ago. 2004. 
GONZÁLEZ GARCÍA, Marta; CEREZO, José López; LUJÁN, José Luján. Ciencia, tecnología y sociedad. Una introducción AL estudio social de la ciencia y la tecnología. Madrid: Tecnos, 1996.

LINSINGEN, Irlan von. Proposta para Implantação do Câmpus UFSC na região do Médio Vale do Itajaí. Documento Interno - UFSC, 2013.

. Perspectiva educacional CTS: aspectos de um campo em consolidação na América Latina. Ciência \& Ensino (UNICAMP), v. 1, pp. 01-16, 2007.

Engenharia, Tecnologia e Sociedade: novas perspectivas para uma formação. 2002. Tese - Centro de Ciências da Educação, Universidade Federal de Santa Catarina, Florianópolis.

MIGNOLO, Walter. Histórias locais/projetos globais. Belo Horizonte: Editora da UFMG, 2003.

MITCHAM, Carl. La importancia de la filosofía para la ingeniería. In: Cerezo, Luján e Palacios (Orgs.). Filosofía de la tecnología. Madrid: OEl, 2001.

NASCIMENTO, Tatiana Galieta; LINSINGEN, Irlan von. Articulações entre o enfoque CTS e a pedagogia de Paulo Freire como base para o ensino de ciências. Convergência: Revista de Ciencias Sociales, año 13, n. 42, set./dez. 2006. México: UAEM. Disponível em: <http://www. uaemex.mx/webvirtual/wwwconver/htdocs/ home.html>. Acesso em: 15 mar. 2014.

ORTIZ, Renato. Mundialização e cultura. 2. Ed. São Paulo: Brasiliense, 1994.

PIMENTA, Selma Garrido; ANASTASIOU, Lea das Graças Camargos. Docência no ensino superior. 2. ed. São Paulo: Cortez, 2005.

SANTOS, Leandro.; ARUTO, Pietro Caldeirini. Boletim Regional do Mercado de Trabalho Mesorregião Vale do Itajaí, Série 2013, n. ${ }^{0} 1$.

THOMAS, Hernán. Sistemas Tecnológicos Sociales y Ciudadanía Socio-Técnica. Innovación, Desarrollo, Democracia. INTA - Córdoba, junio 2011.

VESSURI, Hebe. De la transferencia a la creatividad. Los papeles culturales de la ciencia en los países subdesarrollados. In: IBARRA, A.; CEREZO, J. A. L. Desafíos y tensiones actuales en ciencia, tecnología y sociedad. Madrid: Biblioteca Nueva/OEI, 2001.

Recebido em julho de 2014 Aprovado em dezembro de 2014

Irlan von Linsingen é doutor na área de educação em ciências e professor associado na Universidade Federal de Santa Catarina É líder do Grupo de Pesquisa Discursos da Ciência e da Tecnologia na Educação. E-mail: irlan.vonđufsc.br 